The non-nuclear members of the treaty, already resentful of the dominance of the nuclear powers, will chafe at what seems to be a further assertion of supra-sovereign rights. And that conference is in any case meant to decide whether the NPT should continue in any form. The experience of the past few months has made the NPT seem all the more necessary, but the strains of the same period will probably have further disaffected its non-nuclear members.

\section{Community confusion}

The European Communities have yet to establish a means of supporting research that commands respect.

Signor Filippo Pandolfi, the member of the European Commission responsible for research who is also a vicepresident of the Commission, seems bent on dismantling one of the few research initiatives of which the European Communities (EC) can be proud. It now seems that the Commission is planning to scrap the modest programme of grants for basic research, on which it spends about 35 million ECU a year (about $£ 25$ million), in favour of an ambitious scheme to scatter graduate fellowships around European universities and research institutes (Nature 349, 556; 14 February 1991). Hopes of rescuing some elements of the present research grants scheme (called the SCIENCE programme) rest on tucking them into Pandolfi's plan for graduate fellowships, which entails the choice of 'centres of excellence' throughout Europe. But that solution is at best a second best, and is probably no solution at all.

Most of what the EC spends on research goes on applied research, under schemes for providing 50:50 support for projects in information technology, telecommunications and the like. Collaboration between industrial companies or research institutes in different member states is a prerequisite of support. These projects owe their existence to the mood of the late 1970s, when Europe added to its ambition of achieving industrial parity with the United States the sense of the challenge then presented by Japan. The EC's applied research projects are supposed to be 'pre-competitive' in the sense that they will not lead immediately to saleable products or services, but the definition seems much looser than that used by, for example, the British government for deciding when industry must pay for its own research and development.

Yet these schemes will use up the bulk of the EC's spending under its current framework programme (begun on 1 January 1990), even though circumstances have been radically changed by the prospect of a genuinely free European market from 1 January 1993; that will require industrial companies in different states not to collaborate, but to compete.

That is one reason why there should be a shift in the balance of EC research spending from applied to basic research. Few now dissent. Another is that many parts of the community are at present ill-equipped to play a full part in an increasingly technical future - countries such as Greece, Ireland and Portugal spend so little, nationally, on research support that few of their young people are likely to join Europe's brave new world. On the face of things, Pandolfi's plan for a huge fellowship programme would help meet that need. By being designated as such, centres of excellence would become more excellent, and in the process would also provide research training for people denied opportunities in their home states. That Europe needs some kind of fellowship programme goes without saying. The puzzle is that, to this end, Pandolfi wants to sacrifice the research grants scheme.

That is a thoroughly eccentric ambition which also overlooks one feature of the research-grants scheme that is at once the explanation of its consistent success and a necessary part of all EC decision-making on basic research: decisions on how the (small) pot of money should be spent have been made directly by a committee (called CODEST) of scientists agonizing about the quality of grant proposals, and not by civil servants balancing scientific advice against other considerations, some political. Throughout Western Europe, evaluation of the CODEST kind is a familiar process, which the scientific community takes seriously. It is no wonder that CODEST has won the most outspoken applause for the work it has supported.

So why end such a success, modest though it may have been? It is understandable that a new research commissioner should wish to make a distinctive mark on the apparatus he inherits, but does that imply that all his predecessors' innovations must be scrapped? In justice, the new framework programme should have financed a substantial increase, perhaps a doubling, of the funds that CODEST has to spend, for there has for a long time been too long a tail of good projects that cannot be supported. Is it pique of some kind, or just indifference, that prompts Pandolfi's determination to head off into the uncharted waters of identifying centres of excellence, and then blessing them with fellowships in their gift? Whatever the explanation, one thing seems certain: there will be a hiatus in EC spending on basic research while the issue is talked out in Brussels.

\section{Afraid of flying?}

One of the greatest benefits of technology - cheap air travel - is at risk from market manipulation.

MRs Barbara Bush, the US president's wife, did her bit to rescue US airlines from people's fear of flying by buying herself (and nine attendants) seats on a commercial flight from Washington to Milwaukee. But the airlines' problems go much deeper. Pan American Airlines is protected from its creditors only by enlightened bankruptcy NATURE $\cdot$ VOL $349 \cdot 21$ FEBRUARY 1991 